\title{
Urban versus rural mortality among older adults in China
}

\author{
Zachary Zimmer \\ Population Council \\ Toshiko Kaneda \\ Laura Spess \\ Population Council
}

Follow this and additional works at: https://knowledgecommons.popcouncil.org/departments_sbsr-pgy

Part of the Demography, Population, and Ecology Commons, Family, Life Course, and Society Commons, Gerontology Commons, International Public Health Commons, Medicine and Health Commons, and the Rural Sociology Commons How does access to this work benefit you? Let us know!

\section{Recommended Citation}

Zimmer, Zachary, Toshiko Kaneda, and Laura Spess. 2006. "Urban versus rural mortality among older adults in China," Policy Research Division Working Paper no. 214. New York: Population Council. 


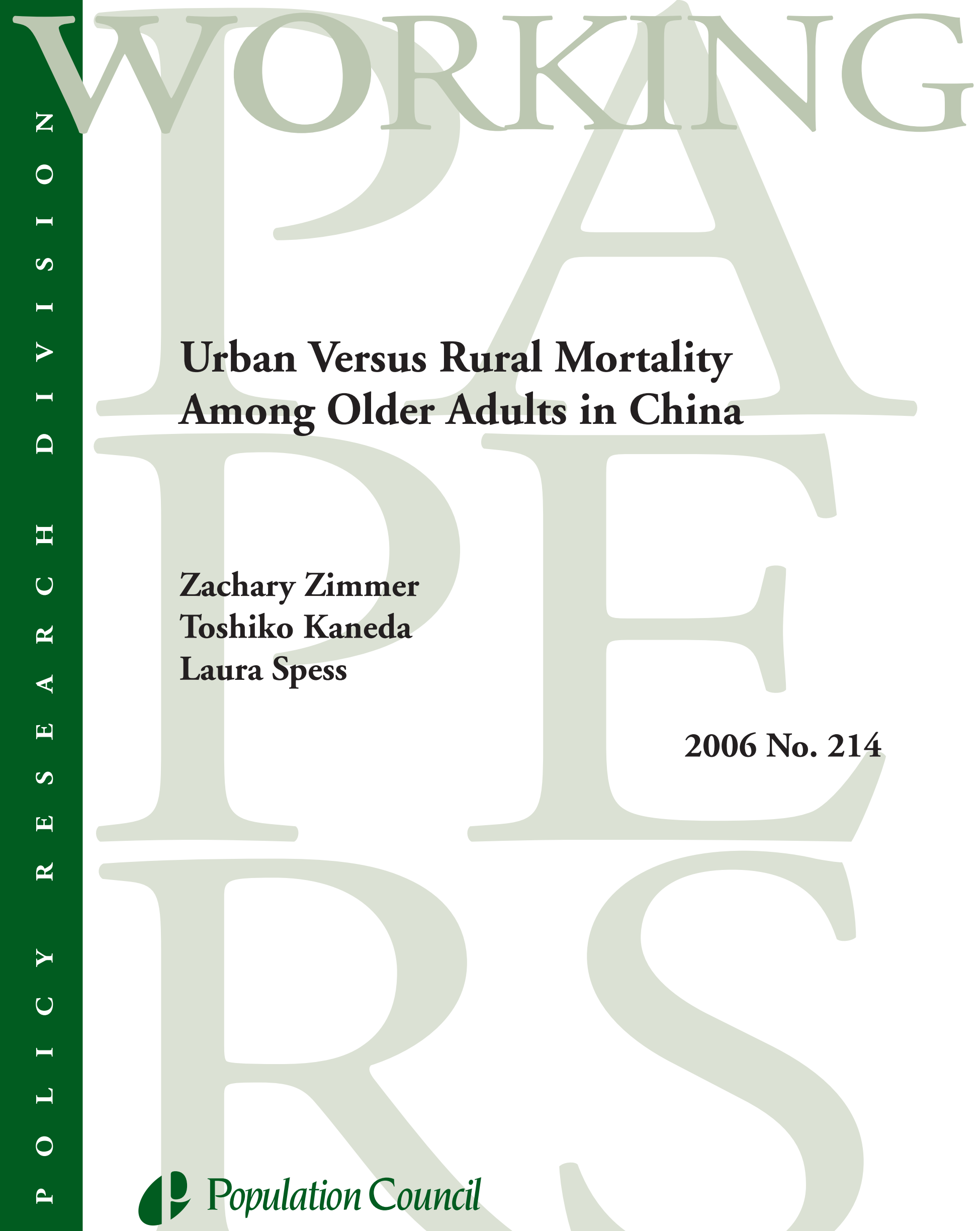




\section{(P) Population Council}

One Dag Hammarskjold Plaza

New York, New York 10017 USA

www.popcouncil.org

pubinfo@popcouncil.org

This material may not be reproduced without written permission from the authors. For a list of Policy Research Division Working Papers, including those that are currently available for downloading in PDF format, see www.popcouncil.org/publications/wp/prd/rdwplist.html.

ISSN: $1554-8538$

(C) 2006 The Population Council, Inc. 


\title{
Urban Versus Rural Mortality Among Older Adults in China
}

\author{
Zachary Zimmer \\ Toshiko Kaneda \\ Laura Spess
}

Zachary Zimmer is Associate and Laura Spess is Research Assistant, Policy Research Division, Population Council. Toshiko Kaneda is Policy Analyst, Population Reference Bureau.

This material may not be reproduced without written permission from the authors. For a list of Policy Research Division Working Papers, including those available for downloading in PDF format, see www.popcouncil.org/publications/wp/prd/rdwplist.html

(C) 2006 The Population Council, Inc. 


\begin{abstract}
Urban versus rural place of residence has proven to be a critical health determinant over time and across countries. Several studies have demonstrated an urban advantage in mortality in China. This variation by place of residence could be a function of differences in characteristics of individuals, differences in urban and rural communities, or a combination of individual and community factors. Population aging, coupled with a growing distinction between urban and rural life, is creating some urgency in the effort to determine the magnitude of the urban advantage among older adults and to ascertain the mechanisms responsible for the association. Using data from the China Health and Nutrition Survey, with additional information from the 2000 Chinese Census, the current study examines urban/rural variation in mortality of adults aged 50 and older. The analysis describes differences in mortality and examines the extent to which variations are accounted for by socioeconomic and health-access and health-availability characteristics that are measured at individual and community levels. Age-specific mortality rates across regions and Cox proportional hazard model ratios are provided using mortality data from 1989 to 2000. Results show unadjusted rural mortality to be 30 percent higher than urban mortality. Adjusting for cadre status and number of amenities within the community reduces the difference to about 18 percent, so that these two covariates account for about 40 percent of the baseline urban advantage.
\end{abstract}


This paper investigates variations in the mortality of older adults across urban and rural areas of China. Urban versus rural place of residence is a critical health determinant; it has been found to distinguish the health experiences of individuals throughout history. Urban/rural residence may be a particularly important determinant in China in light of rapid population aging and widening social and economic disparities between urban and rural areas. These forces have implications for policy because they can alter the balance of formal and informal health-care needs across geographical areas and across age groups. Population aging, which is occurring at an unprecedented rate in China and in other countries in East Asia, results in a greater majority of health problems and mortality occurring at older ages. This aging lends urgency to the effort to ascertain the determinants of health among older adults, the magnitude the urban advantage, and the mechanisms responsible for the association, all important elements in the provision and planning of health care. This analysis describes an urban advantage in older-adult mortality in China and assesses the degree to which a series of covariates account for the variation.

\section{BACKGROUND}

Differences in urban and rural health have been evident since medieval times, when urban residence was harmful owing to the ease of transmission of communicable diseases across populations living in cramped and unsanitary surroundings (Landers 1987; Kearns 1988; National Research Council 2003; Woods 2003). Although recent trends suggest less robust differentials, researchers have noted that an urban mortality advantage still exists in the United States (Kitagawa and Hauser 1973; Clifford and Brannon 1985; Smith et al. 1995; Hayward et al. 1997; House et al. 2000). Yet, urban/rural trends in mortality are available for few developing countries (Eastwood and Lipton 2000; National Research Council 2003). Research suggests a number of public health factors that make city residence in many developing countries advantageous to people's health, such as access to health-care services and to safe water (National Research Council 2003). Moreover, individuals living in urban areas are thought to be socioeconomically better off, earning higher incomes and obtaining higher levels of education, factors considered to be robust predictors of health (Antonovsky 1967; Marmot et al. 1984; Preston and Taubman 1994; Mackenbach et al. 1997). As a result, life expectancy is higher in urban than in rural areas, and urbanites have a lower prevalence of certain diseases and fewer physical functional limitations and disabilities (Andrews 2001; Kinsella 2001; Langmore 2001; National Research Council 2003). Evidence also shows, however, that higher risks for lifestylerelated diseases, such as diabetes and cardiovascular disease, are beginning to arise in some urban areas, and substantial intraurban variations in health are due to urban inequalities (Bradley et al. 1992; Zhai and McGarvey 1992; Harpham and Tanner 1995; Stephens 1996). The urban advantage in the developing world may, in fact, be a tenuous one.

Studies of urban/rural variations in health are hampered by difficulties in defining the precise borders of urban and rural areas, which often encroach upon each other. China, however, is a good example of a country where sharp town/country divisions exist. Chinese urban and rural distinctions are primarily the result of legal designations implemented after the establishment of the People's Republic of China in 1949, notably the household registration system that divided the entire population (Kirkby 1985). Discrete economic, population, social, and health-care policies treated sectors differently, and various advantages, including medical 
coverage and economic investment, accrued to urban areas and to the people living there. In recent years, the urban/rural distinction has been widening, in part as a by-product of China's rapid economic development and subsequent differential investment across regions (England 2005). Urban China is experiencing a well-publicized economic boom, whereas development in rural areas proceeds at a slower pace. The gap in health services has also widened. China's economic reforms during the past couple of decades have produced a decline in the cooperative medical system and an increase in privatized fee-for-services, thus changing the way health care is provided in rural areas. The result is relatively expensive service for rural residents as well as decreasing access to those services (Chen et al. 1993; Shi 1996; Meng et al. 2000; Beach 2001). At the same time, insurance programs financed from the national budget provide subsidized care to urban residents, who thereby have access to qualified medical personnel and are able to draw on an array of medical resources. Indeed, few places in the world experience such sharp urban and rural differences in social and economic life, a reality that has prompted the Chinese government to announce a new focus on strategies aimed at reducing the gaps in economic and social development (Kahn 2004).

Growing social and economic disparities in China apparently intensify existing inequalities in health. A few studies have described an urban advantage that has appeared recently and dates back to the 1960s (Zeng 1990; Fang 1993; Lili 1993; Li and Sun 2003). Mechanisms that account for the urban advantage have been less frequently studied, but are assumed to include higher socioeconomic status and superior access to health-care services. The mechanisms behind the urban advantage appear to operate at individual and community levels.

This study examines urban/rural variation in mortality among adults aged 50 and older in China. It seeks to determine whether an urban advantage in mortality exists for older adults in China, and to what extent such an advantage can be accounted for by socioeconomic and healthservice characteristics that are thought to differentiate individuals and communities.

\section{METHODS}

The China Health and Nutrition Survey (CHNS) is a multiwave longitudinal survey designed to evaluate the health, nutritional, and public health effects of social and economic transformation. The survey is a joint effort of China's National Institute of Nutrition and Food Safety, the Chinese Center for Disease Control and Prevention, and the University of North Carolina at Chapel Hill. To date, the CHNS consists of five waves of data: from 1989, 1991, 1993, 1997, and 2000. The survey employs a multistage random-cluster sampling process to draw households from nine provinces (Guangxi, Guizhou, Heilongjiang, Henan, Hubei, Hunan, Jiangsu, Liaoning, and Shandong). Most households have been followed up across all five waves, but some deletions and additions have occurred based on community participation. In 1989, the CHNS surveyed 15,917 individuals from 3,795 households. The current study is limited to those aged 50 and older; 2,799 such individuals were surveyed for the 1989 wave. Sample sizes are relatively similar across waves. In 1991, the survey followed up the original sampled households. Beginning in 1993 and continuing through subsequent waves, the survey added new households in the sample areas that were formed by individuals included in the previous waves. From 1997 onward, the survey added new households and communities to replace those that were no longer participating. 
This study draws upon data from both community and household modules. A community questionnaire was completed for each primary sampling unit. The questionnaire, completed by knowledgeable respondents, collected information on infrastructure, services, population, and wages. For the household survey, one household member was interviewed, and information was collected about everyone living in the household. This analysis employs both demographic and roster information collected from each household member as well as information collected in the community module.

The data, supporting documentation, and details on sampling for the CHNS are accessed through the Carolina Population Center website: $<$ http://www.cpc.unc.edu/projects/china $>$. The website currently lists 102 publications that have employed CHNS data, few of which focus on older adults and none of which examines mortality. This is an underused resource for questions related to the health of older adults. Publications that provide additional information on the study include Bell et al. (2001), Entwisle and Chen (2002), Wang et al. (2002), and Beydoun and Popkin (2004).

\section{Measuring and analyzing mortality}

At the time of each follow-up, the household register was completed with information about every person who was present at the time of the previous wave's interview. Each individual was listed as alive and still present, having moved, or having died. The month in which a move or death occurred was recorded. Data were missing in cases where households were not contacted, usually when an entire community was no longer participating in the survey.

For the current study, information about household members aged 50 and older was organized into four episodes based on survey intervals (1989-91, 1991-93, 1993-97, and 19972000, and the episodic data were aggregated (see Table 1). Of the 2,799 individuals aged 50 and older in the 1989 sample, 2,435 survived the episode, 105 moved before the next episode, and 109 individuals died. Information about an additional 150 individuals was missing. The analysis is based on an aggregated data set involving 11,439 individuals who were 50 and older at the time of the household interview that began an episode. During the entire survey period, 578 deaths occurred in the total sample of those aged 50 and older.

Exact age is determined by both date of birth and date of interview. An individual aged 48 at the time of interview in 1989 could, depending on his or her date of birth and the date of the interview, enter the sample population for the second interval. In this way, individuals are aged into the sample.

The urban/rural variation in mortality is examined in two ways. Age-specific death rates, calculated as the average yearly rate within age categories, are shown for urban and rural areas. Death rates calculated from the CHNS are compared with tables published from the 2000 Chinese Census and the 2002 UN Demographic Yearbook.

Urban/rural variation in mortality is examined using a Cox proportional hazard model. Survival time is determined by number of months of observation from the start of an episode until time of death or censoring, with those surviving the interval being considered censored at the time of follow-up and those moving being considered censored at the time of their moving. The Breslow method was used for ties, and the suitability of the Cox model was tested visually 
by graphing Kaplan-Meier and Nelson-Aalen estimators and interacting variables with time. None of the variables was found to violate the proportionality assumption. Significance values reported are based on the robust standard errors that account for survey design.

The results of a number of models are provided. Model 1 is a base model that adjusts urban/rural variation by age and sex. Several parameterizations for age were tested, including linear, quadratic, and various spline functions. The best was found to be simply a categorization into five-year intervals. Model 2 is the result of eight models (numbered i to viii), each of which includes base variables plus one of the individual- or community-level covariates. Model 3 is a full model that includes the base and all covariates. Additionally, we examined models that included various combinations of covariates adjusted for age and sex and monitored their impact on the urban/rural coefficient and the degree to which they influenced the $-2 \mathrm{X}$ log-likelihood, which are results used to approximate the explanatory power of covariates. Model 4 is a parsimonious one that includes only those covariates that, when added to the model, substantially reduce the urban/rural coefficient and substantially increase the $-2 \mathrm{X}$ log-likelihood.

\section{Covariates}

Table 2 provides descriptive information about covariates. In addition to age and sex, the covariates represent individual- or community-level characteristics. Individual characteristics are based on the household component of the survey and vary across individuals, even for those living in the same community. Community characteristics are drawn from the community component and are constant across individuals living in the same community. In choosing covariates, we first considered the assumption, noted earlier, that an urban advantage in China could be explained by socioeconomic status and health-care service characteristics. On an individual level, these are indicators of socioeconomic status and access to health service. On a community level, they are indicators of the community's economic status and the availability of health services within the community. Second, our measures had to differentiate people by whether they live in urban or rural areas and differentiate urban and rural communities. Third, our measures had to be consistent across waves.

We use four individual-level measures: education, occupation, cadre status, and having health insurance. Education is measured at three levels: none, some primary, or completed primary and higher. Occupation is categorized as white-collar/skilled work, unskilled/agricultural labor, and other. The "other" category includes student, homemaker, no occupation, or other occupation that is unclassified or difficult to classify; primarily it consists of those not stating an occupation or stating that they have never worked. A cadre is a public official holding a responsible or managerial position in the Communist Party and the government, and therefore may have access to certain privileges. The questionnaire asks whether each household member is a cadre, and this response is coded dichotomously. Finally, the CHNS asks whether each household member has health insurance, and this response is also coded dichotomously. A fair degree of interplay between socioeconomic status and health-service measures is assumed. For instance, those having higher education will have higher socioeconomic standing, and they are also likely to have higher income and a greater understanding of the health-care system than those who are uneducated. These advantages may help them gain access to formal services. Therefore, 
although education is an indicator of socioeconomic status, it is also likely to be a good indicator of access. Having health insurance relates to access in a more direct sense, however.

Four community-level characteristics are considered: number of community amenities, average wage for an unskilled male worker, number of health-care facilities, and distance from the center of the community to the nearest medical facility. The number of amenities is the sum of the following infrastructural items found in the community: telegraph service, telephone service, post office, newspaper, movie theater, paved roads, and 24-hour electricity. The average wage for an unskilled male worker is reported in yuan and is logged for the analysis. About 12 percent of cases with missing responses were imputed using other related community variables. The remaining two community measures relate more directly to availability of health services. Distance from the center of the community to the nearest health-care facility was categorized as less than $1 / 2 \mathrm{~km}, 1 / 2$ to $2 \mathrm{~km}$, and more than $2 \mathrm{~km}$, and a separate code was included for a moderate number of nonresponses (about 15 percent of cases). Number of health-care facilities in the community was determined, eliminating from the count any that were used specifically for reproductive health care.

Other covariates were included in preliminary analyses but were dropped from the final presentation for various reasons, including measurement and interpretation problems. For instance, the amount of missing data for some measures was deemed too great to reconcile. Some measures were inconsistent over time, and others did not fall clearly into the individual- or community-level category. An example is the cost of medical care. This is a community-level measure, but information was collected by asking individuals within households how much they expect to pay for health services. We experimented with aggregating the information from individuals across households within communities, but analytical tests showed that variation within the community was substantial, making the result difficult to interpret. Moreover, determining the cost of medical care as a proportion of income, the measure that would have the clearest meaning for our purpose, is difficult. For these reasons, we excluded the cost of medical care from our final analysis. None of the variables tested in earlier analyses but omitted in the final models was significantly related to mortality, nor did they help to explain the urban/rural variation.

Because episodic information is used, covariates that might carry a different value for the same person or same community over time are treated as time varying in the Cox proportional hazard models. For instance, if an individual does not have insurance in one interval but reports having insurance in the next, the insurance information pertinent to the episode is used in the analysis.

\section{RESULTS}

Table 3 compares age-specific death rates for total, urban, and rural populations from three sources, the CHNS, the 2000 Chinese Census (CC) and the 2002 United Nations Demographic Yearbook 2000 (DY). The table establishes the reliability of the CHNS for measuring mortality and provides an initial descriptive comparison of urban versus rural mortality. Deaths recorded in the DY, which are based on local registration records of vital statistics, are not categorized by urban/rural residence, so that only the total is presented for this source. 
As for reliability, death rates from the CHNS generally correspond to those from the CC and the DY. The bottom row of the table shows the death rates for the $50+$ population as standardized by using a common age and sex distribution (drawn from the CC). The standardized death rate from the CHNS is 24.5, compared with 24.4 for the CC and 22.4 for the DY. CHNS rates are based on an average calculated across the period 1989-2000, whereas the CC is based on deaths reported in 2000 and the DY on those reported in 1999. If the average death rate between 1989 and 1998 were higher than the rate between 1999 and 2000, which would be the case if mortality were on the decline, slightly higher death rates might be expected from the CHNS. Additional analyses, however, revealed that death rates from the CHNS vary considerably across intervals, from a standardized rate of about 20 deaths per 1,000 to 27 deaths. Significant variation over intervals can be expected in light of the relatively small sample size used to calculate the death rate for any interval. So, although the rates for individual intervals are not necessarily reliable, the aggregate of the intervals seems to be. Age-specific death rates from the CHNS are also similar to those from the CC and DY.

Concerning urban/rural variation, both the CHNS and the CC confirm a substantially higher mortality rate for rural areas. Standardized rates for urban areas are calculated to be 21.0 and 20.3 deaths per 1,000 from the CHNS and CC, respectively, which compare with rates of 27.2 and 26.4 deaths per 1,000 for rural areas. Thus, given similar age and sex distributions, we would expect about 30 percent more deaths among the rural elderly. CHNS age-specific results show an advantage for urban residents for five out of seven age groups, at times a substantial advantage. For the $\mathrm{CC}$, rural mortality rates are higher for every age group.

Table 4 presents hazard ratios derived from Cox proportional hazard models. Because of clear expectations regarding associations (for example, urban morality lower than rural; higher education associated with lower mortality; more community amenities associated with lower mortality), one-tailed tests of significance may be as suitable as two-tailed tests. We report the more conventional two-tailed results but note significance up to $\mathrm{p}<0.10$. Model 1 , the base model, shows an odds ratio for rural areas of 1.30; therefore, after controlling for age and sex, mortality is found to be 30 percent higher in rural than in urban areas. The results also show a rapid increase in the hazard of dying with increasing age, and men have a greater risk of dying than women.

The column labeled Model 2 (i-viii) shows partial results for eight models, each of which includes base variables (residence, age, and sex) and one individual-level or community-level covariate. For instance, $2 \mathrm{i}$ includes base variables plus education, 2ii includes base variables plus cadre status, and so on. Only coefficients for the individual- or community-level covariates are shown. Although they are not shown, effects for age and sex remain significant and consistent across all models. The urban/rural effect never declines to insignificance across these models, and its hazard ratio varies between 1.30 and 1.20 depending upon the specific covariate being included.

Three individual-level variables have significant associations with mortality. Cadres have a significantly lower risk of mortality than noncadres, those with unskilled or agricultural occupations and those with occupations categorized as "other" are at higher risk than those with skilled or white-collar occupations, and those with insurance are at lower risk than those without. These findings are all expected. The impact of education is in the expected direction, but it is not statistically significant. This finding is contrary to common understanding based on studies 
conducted elsewhere, although some previous research in China has suggested a limited role for education in determining health outcomes (Liang et al. 2000; Liang et al. 2001; Zimmer and Kwong 2004).

For the community-level variables, only number of amenities, a composite index summing infrastructure items, shows a statistically significant association with mortality, with each additional item decreasing mortality by about 5 percent. Some of the other community-level covariates are in the expected directions. Higher wages within a community decreases the risk of dying, and a longer distance from center of the community to the nearest health facility, specifically more than two kilometers away versus half a kilometer or less, increases the risk. Number of medical facilities available plays virtually no role.

Model 3 is a full model in which all covariates are included simultaneously. The urban advantage is reduced, with the rural odds ratio falling from 1.30 in the base model to about 1.18 in the full model. Of the individual- and community-level covariates, only one of each remains statistically significant. Specifically, being a cadre reduces the hazard of dying, as does living in a community with more amenities.

Model 4 includes the one combination of covariates that accounts most efficiently for the urban advantage. As suggested in the previous model, being a cadre and number of amenities seem to represent best the impact of individual- and community-level factors on mortality. Descriptive results shown above suggest that people in urban areas are more likely to be cadres, and urban communities are more likely to have a greater number of amenities than rural communities. In turn, cadres and those living in communities with more amenities are less likely to die than others, a result that accounts for some of the urban advantage. These two covariates together reduce the hazard of rural residence to 1.18 .

The impact of cadre status and number of amenities on the urban advantage in mortality is shown visually in Figure 1. The figure represents underlying survival curves for a 65-69-yearold woman. The age and sex are chosen for heuristic purposes. A person of different age and sex would have a different but proportional survival curve. Lines representing risks of dying converge for the parsimonious model. For instance, from the base model we determine that after 12 months an urban woman aged 65 to 69 has a 0.9780 probability of survival, compared with 0.9715 for her rural counterpart, an overall difference of 0.0065 . When we hold cadre status and number of amenities constant, the probabilities converge to 0.9730 for the rural woman and 0.9770 for the urban woman, decreasing the difference to 0.0040 . The base model advantage, therefore, is reduced by 38 percent. Survival probabilities after 48 months are 0.9052 and 0.9262 for the base models and 0.9090 and 0.9223 for the parsimonious models, representing a similar decrease in the variation. The remaining 62 percent of the urban advantage is unexplained.

We calculate further, in the same fashion as above, the amount of the initial base model urban advantage that can be explained by the full model, a model that adjusts for only individuallevel covariates, and a model that adjusts for only community-level covariates. The full model decreases the urban advantage by 42 percent, and therefore little additional explanatory power is gained by including all covariates. Individual-level covariates by themselves explain 31 percent and community-level covariates by themselves explain 22 percent of the initial urban advantage. According to this finding, coupled with the results shown in Model 2 of Table 4, the individual- 
level factors appear a bit better able to account for the urban advantage, although this result is not conclusive, particularly in light of the limited number of covariates that we are able to employ.

\section{DISCUSSION}

For some time, Chinese government policies have treated rural and urban areas very differently, and a by-product of China's rapid development seems to be an even greater differentiation between urban and rural social and economic life. While urban China witnesses expansions of infrastructure, less investment has been made in rural China, and availability of rural health services may have declined as a result of the dismantling of the cooperative medical system and the introduction of the pay-for-service policy. Over the next several decades, in part because of rapid fertility declines and in part as a result of mortality declines at older ages, China and other developing countries will experience enormous increases in the proportion of older adults and the proportion of the "oldest-old" (Zeng and George 2001; United Nations 2002a; Kinsella and Phillips 2005). It is reasonable to expect that these age-structure changes will alter the provision of health care, making an understanding of the determinants of health at older ages critical for the development and implementation of policy (Mayhew 1999).

Concentrating mainly on 11 years of available longitudinal data from the China Health and Nutrition Survey, the current study examines variation in mortality between urban and rural China among adults aged 50 and older. Mortality is found to be 30 percent higher in rural areas, controlling for age and sex, based on standardized mortality rates and on results of a Cox proportional hazards model. The advantage is found to be consistent when comparing the CHNS data with those from the 2000 Chinese Census.

The analysis examines the extent to which variables representing socioeconomic and health-service characteristics of individuals and of the communities in which they live can explain the urban advantage. Two characteristics are found to be particularly important. On the individual level, cadre status is influential. Urban residents are more than three times more likely than their rural counterparts to be cadres, and being a cadre appears to be highly beneficial for survival. Cadres' responsible positions within the Communist Party provide them with privileges that are not available to the average Chinese citizen (Lee 1991). For instance, they may have better access to health services, housing, and employment. Moreover, recent economic events may have produced particular benefits for cadres, who are better positioned to take advantage of the change (Nee 1996). As such, cadre status may be a proxy for a host of other socioeconomically related factors not accounted for in the current study. Cadre status might also relate to psychological resources that can influence health, such as level of stress, feelings of control, and feelings of self-worth. That cadres have lower mortality than others is unsurprising, but that cadre status is such an important determinant in comparison with education, occupation, and having insurance is surprising. The results presented here support a long-standing and wellrecognized finding in other parts of the world about the connection between socioeconomic status and mortality (Antonovsky 1967; Marmot et al. 1984; Preston and Taubman 1994; Mackenbach et al. 1997). Moreover, they suggest that the specific indicator of socioeconomic status that is critical may be culturally dependent. 
At the community level, the important measure is the number of amenities available to residents. Urban communities have, on average, a greater number of amenities than rural communities, and individuals living in communities with a large number of amenities have a lower risk of mortality. As noted above, the number of amenities is an indicator of wealth and resources available within a community as well as of the remoteness of a community. These amenities may also be a proxy for other services, including some that are related to health. Some of the amenities in our measure, such as telephone service, facilitate communication, whereas others, such as paved roads, facilitate transportation. Both of these factors may be important for transferring health-related information to older adults, moving both formal and informal care into the community and allowing older adults to be in contact with family members elsewhere, which likely have psychological benefits and result in more efficient informal assistance when it is needed.

We ran additional Cox models to predict survival in light of the existence versus nonexistence of each amenity, adjusting for age, sex, and residence. Telegraph service, electricity, telephone service, and paved roads were found to be most important, in that order, and post office, movie theater, and newspapers least important. One explanation for these findings is that the most important amenities are those that facilitate communication and transportation. A second is that a movie theater or newspaper may be established in a community only after more basic infrastructure such as telephone service and paved roads are in place, developments that are more crucial for health care. This ordering of amenities suggests a threshold for infrastructure above which communities become equal. Nevertheless, the summed score of these seven items proves to be the best indicator for the association with older adult mortality. The policy implication of this finding is clear: investment in rural infrastructure and economy would have a beneficial role in reducing health inequalities, particularly for the poorest and most remote communities.

Although a greater number of infrastructural amenities resulted in lower mortality, the number of a community's medical facilities had virtually no influence. Perhaps the number of facilities alone does not determine the quality of service available. Small facilities, although numerous, may be poorly maintained and equipped and staffed with poorly qualified personnel. At the same time, large facilities, even if fewer in number, may provide better medical treatment, may be technologically more advanced, and may be able to handle a wider range of health problems.

As noted above, evidence indicates that availability of health-care services in rural China has remained static or even deteriorated, while the gap in socioeconomic inequalities between urban and rural areas has widened. Using the four survey intervals of the CHNS, we conducted additional analyses to determine whether we could find evidence of a widening of the urban advantage in mortality over time. The results are inconclusive. Virtually no change was found in the risk of death or in the urban/rural gap from 1989 through 1997. The last interval, 1997-2000, shows a marked decline in mortality overall and a widening of the urban/rural gap, but the latter is not statistically significant. Moreover, we are not convinced that anything other than the aggregated sample is reliable.

Several issues regarding covariates should be noted. First, the current study employs a limited number of variables. Inclusion is based on criteria such as consistent measurement over 
time and whether they distinguish rural from urban residents. Clearly, other possible individualand community-level covariates might be important for explaining the variation in older adult mortality in China, but they were unavailable to us. Some additional covariates were tested, but results were not interpretable. Inclusion of other covariates might change our view concerning whether individual- or community-level predictors work best. Factors beyond those related to socioeconomic and health services, such as differences in social support or health-care-seeking behaviors, might hold promise for explaining variation in mortality across urban and rural China. Nevertheless, with a small number of covariates we are able to account for about two-fifths of the urban advantage.

Second, some fairly high correlations are found among our covariates, specifically: having higher than a primary education and having a skilled occupation $(\mathrm{r}=0.41)$; having higher than a primary education and being a cadre $(\mathrm{r}=0.33)$; having a skilled occupation and being a cadre $(r=0.39)$; having a skilled occupation and having insurance $(r=0.43)$; number of health facilities and distance to a health facility of 0.50 kilometers or closer to the center of the community $(\mathrm{r}=0.38)$; and having an unskilled occupation and number of amenities in a community $(\mathrm{r}=-0.34)$. This "shared variance" might be one factor accounting for relatively weak significance among some covariates in our full model.

Third, some results are curious. Having an occupation in the "other" category in comparison with a skilled/white-collar occupation increases the risk of mortality. This result is difficult to interpret because the "other" category comprises mostly responses from those who never worked or those who did not state an occupation. In addition, although the effect of having health insurance is clear when other individual-level covariates are not controlled, its insignificance in the full model defies common sense.

As a final note, we must be cautious about the accuracy of mortality reporting in China. Prior research suggests that census and vital registration data in China tend to underestimate number of deaths (Banister and Hill 2004; Yang et al. 2005). Indeed, a footnote in the UN Demographic Yearbook declares that death rates are inflated in order to calculate life expectancies for China because the underreporting of deaths in vital registration is assumed. Nevertheless, because death rates in the China Health and Nutrition Survey mirror to a great degree those in the census and the Demographic Yearbook, we speculate that whatever inaccuracies exist in the CHNS parallel those in these other sources. Moreover, underreporting is thought to be greater in rural than in urban areas. If this were the case, then the results shown here could represent an underestimation of the urban advantage in mortality. 
Table 1 Number of individuals aged 50 and older, by survey interval, according to survival status, China Health and Nutrition Survey

\begin{tabular}{|c|c|c|c|c|c|}
\hline Survey interval & Starting $\mathbf{N}$ & $\begin{array}{r}\text { Survived, lived in } \\
\text { same residence at } \\
\text { end of interval } \\
\end{array}$ & $\begin{array}{r}\text { Survived, } \\
\text { moved before } \\
\text { end of interval } \\
\end{array}$ & Died & $\begin{array}{r}\text { Status } \\
\text { unknown } \\
\end{array}$ \\
\hline 1989-91 & 2,799 & 2,435 & 105 & 109 & 150 \\
\hline 1991-93 & 2,742 & 2,351 & 52 & 131 & 208 \\
\hline 1993-97 & 2,708 & 1,826 & 104 & 185 & 593 \\
\hline 1997-2000 & 3,190 & 2,464 & 129 & 153 & 444 \\
\hline Total & 11,439 & 9,076 & 390 & 578 & 1,395 \\
\hline
\end{tabular}


Table 2 Percentage of individuals surveyed, by selected demographic, individual, and community variables, according to rural/urban residence, China Health and Nutrition Survey

\begin{tabular}{|c|c|c|}
\hline Variable & $\begin{array}{l}\text { Rural } \\
(\mathrm{N}=6,671)\end{array}$ & $\begin{array}{l}\text { Urban } \\
(\mathrm{N}=\mathbf{3 , 3 7 1})\end{array}$ \\
\hline \multicolumn{3}{|l|}{ Demographic } \\
\hline Mean age & 62.5 & $61.9 * * *$ \\
\hline \multicolumn{3}{|l|}{ Sex } \\
\hline Male & 48.2 & 47.1 \\
\hline \multicolumn{3}{|l|}{ Individual } \\
\hline \multicolumn{3}{|l|}{ Education } \\
\hline None & 51.7 & $42.0 * * *$ \\
\hline Primary & 35.6 & $33.8 *$ \\
\hline Primary+ & 12.8 & $24.2 * * *$ \\
\hline Is a cadre & 2.7 & $7.7 * * *$ \\
\hline \multicolumn{3}{|l|}{ Occupation } \\
\hline White collar/skilled & 10.2 & $25.9 * * *$ \\
\hline Unskilled/agricultural & 68.1 & $44.0 * * *$ \\
\hline Never worked/other/missing & 21.7 & $30.2 * * *$ \\
\hline \multicolumn{3}{|l|}{ Insurance } \\
\hline Has insurance & 18.3 & $53.3 * * *$ \\
\hline \multicolumn{3}{|l|}{ Community } \\
\hline Number of amenities & 3.9 & $5.1 * * *$ \\
\hline $\begin{array}{l}\text { Average wage for unskilled male worker } \\
\text { (in yuan) }\end{array}$ & 13.0 & $14.9 * * *$ \\
\hline Mean number of medical facilities & 2.0 & $3.0 * * *$ \\
\hline \multicolumn{3}{|l|}{ Distance to nearest medical facility } \\
\hline $0-0.50 \mathrm{~km}$ & 50.6 & $47.6 * * *$ \\
\hline $0.51-2.00 \mathrm{~km}$ & 30.9 & $27.2 * * *$ \\
\hline $2.01+\mathrm{km}$ & 10.6 & 10.1 \\
\hline Missing information & 7.9 & $15.2 * * *$ \\
\hline
\end{tabular}

*Significant at $\mathrm{p}<0.10 ; * * \mathrm{p}<0.05 ; * * * \mathrm{p}<0.01$, comparing urban and rural data, two-tailed test. 
Table 3 Age-specific death rates per 1,000 population by urban/rural residence, according to source of data, China

\begin{tabular}{|c|c|c|c|c|c|c|c|}
\hline \multirow[b]{2}{*}{ Age } & \multicolumn{3}{|c|}{ CHNS } & \multicolumn{3}{|c|}{$2000 C^{a}$} & \multirow{2}{*}{$\begin{array}{l}\frac{D^{\prime} Y^{b}}{\text { Total }} \\
\text { population }\end{array}$} \\
\hline & $\begin{array}{l}\text { Total } \\
\text { population }\end{array}$ & Urban & Rural & $\begin{array}{l}\text { Total } \\
\text { population }\end{array}$ & Urban & Rural & \\
\hline $50-54$ & 6.7 & 5.7 & 7.1 & 5.5 & 4.3 & 6.1 & 4.6 \\
\hline $55-59$ & 11.2 & 8.9 & 12.4 & 8.7 & 6.9 & 9.6 & 8.6 \\
\hline $60-64$ & 15.7 & 9.5 & 19.1 & 14.8 & 11.7 & 16.5 & 15.3 \\
\hline $65-69$ & 22.2 & 22.5 & 22.3 & 24.4 & 20.1 & 26.6 & 24.3 \\
\hline $70-74$ & 44.8 & 27.8 & 59.9 & 42.3 & 35.2 & 45.8 & 38.4 \\
\hline $75-79$ & 65.3 & 59.8 & 69.9 & 66.5 & 56.2 & 71.2 & 57.6 \\
\hline $80+$ & 119.0 & 127.1 & 116.1 & 134.5 & 117.0 & 142.8 & 117.7 \\
\hline $\begin{array}{l}\text { Standardized } \\
\mathrm{DR}^{\mathrm{c}}\end{array}$ & 24.5 & 21.0 & 27.2 & 24.4 & 20.3 & 26.4 & 22.4 \\
\hline
\end{tabular}

${ }^{a}$ China Data Center. 2006. China Data Online. Tables 6a, 6b, 6c.

${ }^{\mathrm{b}}$ United Nations (2002b). Tables 7 and 19.

${ }^{\mathrm{c}}$ Standardized death rate using the age composition of the total sample in the 2000 census. 
Table 4 Cox models showing hazard ratios for dying, by selected variables, China

\begin{tabular}{|c|c|c|c|c|}
\hline Variable & $\begin{array}{c}\text { Model } 1 \\
\text { Base }\end{array}$ & $\begin{array}{c}\text { Model 2 } \\
\text { (i-viii) Single } \\
\text { covariates }^{\mathrm{a}}\end{array}$ & $\begin{array}{c}\text { Model } 3 \text { Full } \\
\text { model }\end{array}$ & $\begin{array}{c}\text { Model } 4 \\
\begin{array}{c}\text { Parsimonious } \\
\text { model }\end{array} \\
\end{array}$ \\
\hline \multicolumn{5}{|l|}{ Residence } \\
\hline Urban (r) & 1.00 & & 1.00 & 1.00 \\
\hline Rural & $1.30 * *$ & & 1.18 & $1.18^{*}$ \\
\hline \multicolumn{5}{|l|}{ Age } \\
\hline $50-54(\mathrm{r})$ & 1.00 & & 1.00 & 1.00 \\
\hline $55-59$ & $1.40^{*}$ & & $1.38^{*}$ & $1.41^{*}$ \\
\hline $60-64$ & $1.77 * * *$ & & $1.72 * * *$ & $1.79 * * *$ \\
\hline $65-69$ & $3.69^{* * *}$ & & $3.54 * * *$ & $3.72 * * *$ \\
\hline $70-74$ & $5.49 * * *$ & & $5.11^{* * *}$ & $5.45^{* * *}$ \\
\hline $75-79$ & $9.40^{* * *}$ & & $8.49^{* * *}$ & $9.26 * * *$ \\
\hline $80+$ & $17.55 * * *$ & & $15.38 * * *$ & $17.24 * * *$ \\
\hline \multicolumn{5}{|l|}{ Sex } \\
\hline Male (r) & 1.00 & & 1.00 & 1.00 \\
\hline Female & $1.46^{* * *}$ & & $1.60^{* * *}$ & $1.50^{* * *}$ \\
\hline \multicolumn{5}{|l|}{ Education } \\
\hline None & & 1.24 & 1.03 & \\
\hline Primary & & 1.11 & 0.97 & \\
\hline Primary+ (r) & & 1.00 & 1.00 & \\
\hline \multicolumn{5}{|l|}{ Is a cadre } \\
\hline No $(r)$ & & 1.00 & 1.00 & 1.00 \\
\hline Yes & & $0.39 * *$ & $0.47^{*}$ & $0.41 * *$ \\
\hline \multicolumn{5}{|l|}{ Occupation } \\
\hline White collar/skilled & & 1.00 & 1.00 & \\
\hline Unskilled/agricultural & & $1.44 * * *$ & 1.17 & \\
\hline Never worked/other/missing & & $1.54^{* * *}$ & 1.38 & \\
\hline \multicolumn{5}{|l|}{ Has insurance } \\
\hline No $(r)$ & & 1.00 & 1.00 & \\
\hline Yes & & $0.81 * *$ & 0.93 & \\
\hline Log average wage for unskilled male worker & & 0.96 & 0.98 & \\
\hline Number of amenities & & $0.95^{* * *}$ & $0.95 * *$ & $0.95 * * *$ \\
\hline Number of medical facilities & & 1.01 & 0.98 & \\
\hline \multicolumn{5}{|l|}{ Distance to nearest medical facility } \\
\hline $0-0.50(\mathrm{r})$ & & 1.00 & 1.00 & \\
\hline $0.51-2.00$ & & 1.02 & 1.03 & \\
\hline $2.01+\mathrm{km}$ & & 1.26 & 1.18 & \\
\hline Missing distance information & & 0.78 & 0.84 & \\
\hline Log-likelihood & $-4,908.7$ & & $-4,895.3$ & $4,901.5$ \\
\hline$\Delta-2 \mathrm{LL}$ from base & & & $26.8 * * *$ & $14.3 * * *$ \\
\hline
\end{tabular}

*Significant at $\mathrm{p}<0.10 ; * * \mathrm{p}<0.05 ; * * * \mathrm{p}<0.01 . \quad(\mathrm{r})=$ Reference category.

${ }^{a}$ Results represent a series of models all of which adjust for residence, age, and sex. Results for residence, age, sex, log-likelihood, and $\Delta-2 \mathrm{LL}$ not shown. ${ }^{\mathrm{b}}$ Addition of other covariates does not substantially change the urban coefficient or the $\Delta-2 \mathrm{LL}$ from base. 
Figure 1 Implied survival curves for a 65-69-year-old Chinese woman, by urban and rural residence, assuming base and parsimonious models

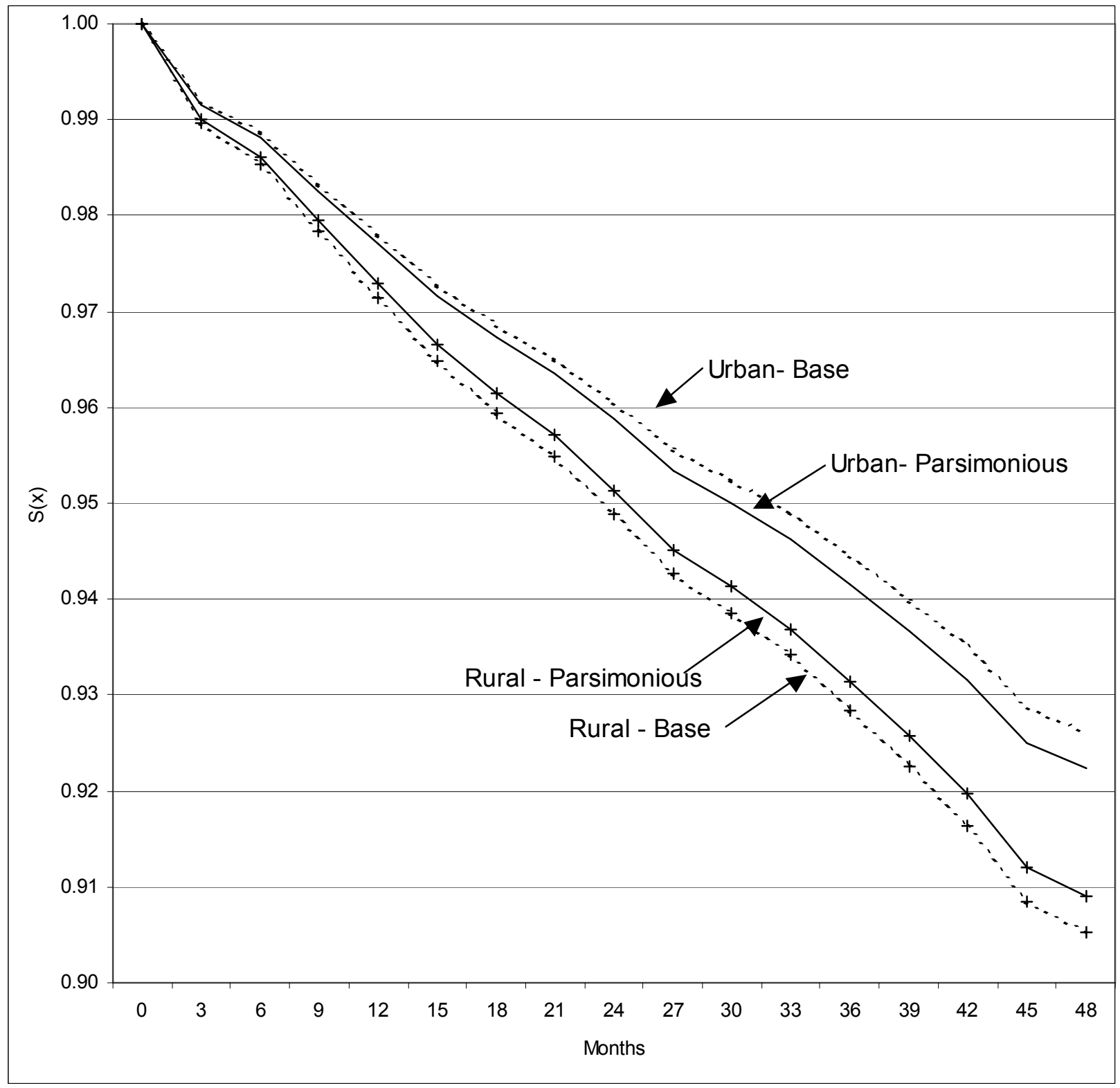




\section{REFERENCES}

Andrews, G.R. 2001. "Demographic and health issues in rural aging: A global perspective." The Journal of Rural Health 17: 323-327.

Antonovsky, A. 1967. "Social class, life expectancy and overall mortality." Milbank Memorial Fund Quarterly 45: 31-73.

Banister, J. and K. Hill. 2004. "Mortality in China 1964-2000." Population Studies 58: 55-75.

Beach, M. 2001. "China's rural health care gradually worsens." Lancet 358: 567.

Bell, A.C., K. Ge, and B.M. Popkin. 2001. "Weight gain and its predictors in Chinese adults." International Journal of Obesity 25: 1,079-1,086.

Beydoun, M.A. and B.M. Popkin. 2005. "The impact of socio-economic factors on functional status decline among community-dwelling older adults in China." Social Science \& Medicine 60: 2,045-2,057.

Bradley, J.B, T. Stephens, T. Harpham, and S. Cairncross. 1992. A Review of Environmental Health Impacts in Developing Country Cities. Washington, DC: The World Bank.

Chen, X.M., T.W. Hu, and Z. Lin. 1993. "The rise and decline of the cooperative medical system in rural China." International Journal of Health Services 23: 731-742.

China Data Center. 2006. China Data Online. Ann Arbor: University of Michigan. $<$ http://chinadataonline.org>. Accessed 26 April 2006.

Clifford, W.B. and Y.S. Brannon. 1985. "Rural-urban differences in mortality." Rural Sociology 50: $210-224$.

Eastwood, R. and M. Lipton. 2000. "Rural Urban Dimensions of Inequality Change." United Nations University World Institute for Development Economic Research Working Paper No. 200. Helsinki: UWU.

England, R.S. 2005. Aging China: The Demographic Challenge to China's Economic Prospects. Westport, CT: Praeger Publishers.

Entwisle, B. and F. Chen. 2002. "Work patterns following a birth in urban and rural China: A longitudinal study." European Journal of Population 18: 99-119.

Fang, R.K. 1993. "The geographical inequalities of mortality in China." Social Science \& Medicine 36: 1,319-1,323.

Harpham, T. and M. Tanner (eds.). 1995. Urban Health in Developing Countries: Progress and Prospects. New York: St. Martin's Press.

Hayward, M.D., A.M. Pienta, and D. K. Mclaughlin. 1997. "Inequality in men's mortality: The socioeconomic status gradient and geographic context." Journal of Health and Social Behavior 38: 313-330. 
House, J.S., J.M. Lepkowski, D.R. Williams, R.P. Mero, P.M. Lantz, S.A. Robert, and J. Chen. 2000. "Excess mortality among urban residents: How much, for whom, and why?" American Journal of Public Health 90: 1,898-1,904.

Kahn, J. 2004. “China's leader urges shift in development to rural areas.” New York Times 5 March: 6.

Kearns, G. 1988. "The urban penalty and the population history of England." In Society, Health and Population During the Demographic Transition. Eds. A. Brandstrom and L. Tedebrand. Stockholm: Almquist and Wiskell International. Pp. 213-236.

Kinsella, K. 2001. "Urban and rural dimensions of global population aging: An overview." The Journal of Rural Health 17: 314-322.

Kinsella, K. and D.R. Phillips. 2005. "Global aging: The challenge of success." Population Bulletin 60: 1-40.

Kirkby, R.J.R. 1985. "The definition of urban population in the People's Republic of China.” In Urbanization in China: Town and Country in a Developing Economy, 1949-2000 A.D. Ed. R.J.R. Kirby. New York: Columbia University Press. Pp. 54-102.

Kitagawa, E.M. and P.M. Hauser. 1973. Differential Mortality in the United States: A Study of Socioeconomic Epidemiology. Cambridge: Harvard University Press.

Landers, J. 1987. "Mortality and metropolis: The case of London 1675-1825.” Population Studies 41: 59-76.

Langmore, J. 2001. "Rural aging: A global challenge.” Journal of Rural Health 17: 305-306.

Lee, H.Y. 1991. From Revolutionary Cadres to Party Technocrats in Socialist China. Berkeley, CA: University of California Press.

Liang, J, X. Liu, and S. Gu. 2001. "Transitions in functional status among older people in Wuhan, China: Socioeconomic differentials." Journal of Clinical Epidemiology 54: 1,126-1,138.

Liang, J., J.F. McCarthy, A. Jain, N. Krause, J.M. Bennett, and S. Gu. 2000. "Socioeconomic gradient in old age mortality in Wuhan, China." Journal of Gerontology: Social Sciences 55B: 222-233.

Li, S. and F. Sun. 2003. "Mortality analysis of China's 2000 population census data: A preliminary examination." The China Review 3: 31-48.

Lili, M. 1993. "Analysis of social and economic factors affecting mortality in China." Chinese Journal of Population Science 5: 119-132.

Mackenbach J.P., A.E. Kunst, A.E.J.M. Cavelaars, F. Groenhof, J.J.M. Geurts, and the EU Working Group on Socioeconomic Inequalities in Health. 1997. "Socioeconomic inequalities in morbidity and mortality in western Europe.” The Lancet 349: 1,655-1,659. 
Marmot M.G., M. Shipley, and G. Rose. 1984. "Inequalities in death: Specific explanations of a general pattern?" Lancet 1: 1,003-1,006.

Mayhew, L. 1999. "Health and welfare services expenditure in an aging world." Interim Report \# IR-99-035. Laxenburg, Austria: International Institute for Applied Systems Analysis.

Meng, Q., X. Liu, and J. Shi. 2000. "Comparing the services and quality of private and public clinics in rural China." Health and Policy Planning 15: 349-356.

National Research Council. 2003. Cities Transformed: Demographic Change and Its Implications in the Developing World. Washington, DC: The National Academies Press.

Nee, V. 1996. "The emergence of a market society: Changing mechanisms of stratification in China." American Journal of Sociology 101: 908-949.

Preston S.H. and P. Taubman. 1994. "Socioeconomic differences in adult mortality and health status." In Demography of Aging. Eds. L.G. Martin and S.H. Preston. Washington, DC: National Academies Press. Pp. 279-318.

Shi, L. 1996. "Access to care in post-economic reform rural China: Results from a 1994 crosssectional survey." Journal of Public Health Policy 17: 347-361.

Smith, M.H., R.T. Anderson, D.D. Bradham, and C.F. Longino. 1995. "Rural and urban differences in mortality among Americans 55 years and older: Analysis of the national longitudinal mortality study." The Journal of Rural Health 11: 274-285.

Stephens, C. 1996. "Healthy cities or unhealthy islands? The health and social implications of urban inequality." Environment and Urbanization 8: 9-30.

United Nations. 2002a. World Population Ageing 1950-2050. New York: UN.

—. 2002b. Demographic Yearbook 2000. New York: UN.

Wang, Y., M.E. Bentley, F. Zhai, and B.M. Popkin. 2002. "Tracking of dietary intake patterns of Chinese from childhood to adolescence over a six-year follow-up period." Journal of Nutrition 132: 430-438.

Woods, R. 2003. "Urban-rural mortality differentials: An unresolved debate." Population and Development Review 29(1): 29-46.

Yang, G., J. Hu, K.Q. Rao, J. Ma, C. Rao, and A.D. Lopez. 2005. "Mortality registration and surveillance in China: History, current situation and challenges." Population Health Metrics 3: 1-9.

Zeng, Y. 1990. "An analysis of changing trends in China's urban and rural households." Chinese Journal of Population Science 2: 187-199.

Zeng, Y. and L.K. George. 2001. "Extremely rapid ageing and the living arrangements of the elderly: The case of China." Population Bulletin of the United Nations (42/43): 255-287. 
Zhai, S. and S.T. McGarvey. 1992. "Temporal changes and rural-urban differences in cardiovascular disease risk factors and mortality in China." Human Biology 64: 807-819.

Zimmer, Z. and J. Kwong. 2004. "Socioeconomic status and health among older adults in rural and urban China." Journal of Aging and Health 16: 44-70. 


\section{POLICY RESEARCH DIVISION WORKING PAPERS}

If still in print, single copies of up to three working papers from 1989 through 2003 are available free of charge.

Beginning with the 2004 issues, working papers are no longer available in print format. Instead they are distributed electronically. As each new paper is completed subscribers are notified by e-mail and a link to the paper is provided.

To subscribe to the Policy Research Division working paper e-mail notification list, or to obtain back issues from 1989 to 2003, please send your request to prdwp@popcouncil.org.

PDFs of recent issues are available at www.popcouncil.org/publications/wp/prd/rdwplist.html

2006

214 Zachary Zimmer, Toshiko Kaneda, and Laura Spess, "Urban versus rural mortality among older adults in China."

213 Paul Demeny and Geoffrey McNicoll, "The political demography of the world system, 2000-2050."

212 Monica Grant and Kelly Hallman, "Pregnancy-related school dropout and prior school performance in South Africa."

211 Kelly Hallman, Sara Peracca, Jennifer Catino, and Marta Julia Ruiz, "Multiple disadvantages of Mayan females: The effect of gender, ethnicity, poverty, and residence on education in Guatemala."

210 Geoffrey McNicoll, "Policy lessons of the East Asian demographic transition."
209 Cynthia B. Lloyd, Cem Mete, and Monica J. Grant, "The implications of changing educational and family circumstances for children's grade progression in rural Pakistan: 1997-2004."

2005

208 James F. Phillips, Ayaga A. Bawah, and Fred N. Binka, "Accelerating reproductive and child health program development: The Navrongo Initiative in Ghana."

207 John Bongaarts and Griffith Feeney, "The quantum and tempo of life-cycle events."

206 Barbara S. Mensch, Monica J. Grant, and Ann K. Blanc, "The changing context of sexual initiation in sub-Saharan Africa."

205 Geoffrey McNicoll, "Population and sustainability."

204 John Bongaarts, "The causes of stalling fertility transitions." 
Binka, "How many years of life could be saved if malaria were eliminated from a hyperendemic area of northern Ghana?"

202 Barbara S. Mensch, Susheela Singh, and John B. Casterline, "Trends in the timing of first marriage among men and women in the developing world."

201 Zachary Zimmer, "Active life expectancy and functional limitations among older Cambodians: Results from a 2004 survey."

200 Brian Wells Pence, Philomena Nyarko, James F. Phillips, and Cornelius Debpuur, "The effect of community nurses and health volunteers on child mortality: The Navrongo Community Health and Family Planning Project."

199 Zachary Zimmer, Linda G. Martin, Mary Beth Ofstedal, and Yi-Li Chuang, "Education of adult children and mortality of their elderly parents in Taiwan."

198 Mian Bazle Hossain, James F. Phillips, and Thomas K. LeGrand, "The impact of childhood mortality on fertility in six rural thanas of Bangladesh."

197 Kristine R. Baker, Mary Beth Ofstedal, Zachary Zimmer, Zhe Tang, and Yi-Li Chuang, "Reciprocal effects of health and economic well-being among older adults in Taiwan and Beijing."

196 Mark R. Montgomery and Paul C. Hewett, 'Poverty and children's schooling in urban and rural Senegal."

195 Luciana Suran, Sajeda Amin, Lopita Huq, and Kobita Chowdury, "Does dowry improve life for brides? A test of the bequest theory of dowry in rural Bangadesh."

194 Barbara S. Mensch, Monica J. Grant, Mary P. Sebastian, Paul C. Hewett, and Dale Huntington. "The effect of a livelihoods intervention in an urban slum in India: Do vocational counseling and training alter the attitudes and behavior of adolescent girls?"

93 Amanda Ritchie, Cynthia B. Lloyd, and Monica Grant. "Gender differences in time use among adolescents in developing countries: Implications of rising school enrollment rates."

192 John Bongaarts. "Long-range trends in adult mortality: Models and projection methods."

191 John Koku Awoonor-Williams, Ellie S. Feinglass, Rachel Tobey, Maya N. Vaughan-Smith, Frank K. Nyonator, Tanya C. Jones, and James F. Phillips, "Bridging the gap between evidence-based innovation and national healthsector reform in Ghana."

190 Kelly Hallman, "Socioeconomic disadvantage and unsafe sexual behaviors among young women and men in South Africa."

189 Toshiko Kaneda, Zachary Zimmer, and Zhe Tang, "Differentials in life expectancy and active life expectancy by socioeconomic status among older adults in Beijing." 
188 Cynthia B. Lloyd and Monica J.

Grant, "Growing up in Pakistan:

The separate experiences of males and females."

187 Zachary Zimmer, Xianghua Fang, Toshiko Kaneda, Zhe Tang, and Julia Kwong. "Trends and transitions in children's coresidence with older adults in Beijing municipality."

186 Sajeda Amin and Alaka M. Basu. "Popular perceptions of emerging influences on mortality and longevity in Bangladesh and West Bengal."

185 John Bongaarts. "Population aging and the rising cost of public pensions."

184 Mark R. Montgomery and Paul C. Hewett. "Urban poverty and health in developing countries: Household and neighborhood effects." 